\title{
Factors of Quality Management Affecting the Implementation of QM in Supply Chain Using Analytical Hierarchy Process (AHP) Approach
}

\author{
Ankur Sharma and Ravi
}

\begin{abstract}
Quality management (QM) is generally observed as a philosophy that goals to achieve customer satisfaction through continuous improvement and team work. The conversion towards QM is coupled with its spread, from the manufacturing to the service sector and onto public services (Dale, 1999) Implementation of QM becomes a top management plan in many organizations in the pursuit of positive business benefits, such better product quality, higher customer satisfaction and minimum quality cost and enhance supply chain. Some recent studies uphold that many organizations launched QM programs have increase positive results. There have been several approaches and model suggested for the QM introduction and implementation. This paper presents main finding of a recent study that investigated the critical factors of quality management affecting the implementation of QM in supply chain. This study seek to identify the critical factors and sub factors to implement quality management in supply chain using analytical hierarchy process (AHP) approach. A general hierarchy model was expanded to help prioritization these factors and formulate approach for quality management implementation in supply chain.
\end{abstract}

Keywords--- Quality Management, Supply Chain Management, Analytical hierarchy process, Total Quality Management

\section{INTRODUCTION}

$\mathrm{T}$ HERE is a growing concentration on global supply chain management. Supply chain management is a whole and a strategic approach to demand, operations, procurement, and logistics process management (Kueiet al., 2001). Traditionally, the focus of supply chains was on specific functionalities such as purchasing, manufacturing, and shipping to support logistics operations. The competitive environment requires the delivery of cost, efficiency, high service levels, very quick response, and good quality of products and services. The productive management of quality is the key to increased quality and improve competitive position in today's global environment. Kuei et al. (2001) told that quality management compliance should be recognised from supply chain management.

Ankur Sharma, Assistant Professor, Mechanical Dept., HMR Institute of Technology \& Management, Delhi, India. E-mail:er.ankurncce@gmail.com Ravi, Assistant Professor, Mechanical Dept., HMR Institute of Technology \& Management, Delhi, India.E-mail:ravisharma13@ymail.com DOI: $10.9756 / \mathrm{BIJIEMS.10451}$

\section{LITERATURE REVIEW}

Over the last fifteen years, supply chain management (SCM) has taken a range of directions with different outcomes. (Tompkins, J.A. 2000) said that SCM process has not produced the better outcomes since then; many researchers have appeared in various channels with interesting discovered. Fynes and Voss, (2002) told the impact of quality management on supply chain performance. Based on their empirical study, the authors Claim that with business conditions becoming more getting much out. It is imperative to realize that stronger relation quality is a must to get done higher supply chain doing a play.

Campbell and Sankaran, (2005) discussed the combination issues of supply chains for small and medium size industries. The authors make ready a framework to help such a united as complete thing process for use and observations by expert and persons making observations alike. He also analysed the problem that changes in customer preferences demand customization of products, and how information will share beneath such assets can aid in improvement of quality in supply chain performance. This paper also analyses strategic issues for industry supply chains and quality management. Although special to a person market place, this paper takes out key SCM issues and proposes a great number of starting ideas that must be made observations by future studies interested in the area of complete supply chains. Based on this study, the authors concluded that there is a firm bonding between quality management and supply management that affects business operations.

Since the 1980s, quality has become a major influence in the business world. Although, in general, for the major companies it all began with applying the theories of the quality gurus, especially doctors Deming and Juran, it is also true that the definitive push, especially for the small and medium-size companies, came about with the appearance of the quality assurance standard, ISO 9000. Without doubt, its increasing putting into effect in companies all over the world continues to be the main driving force behind improvements in quality management. At present, the private road to get this ISO 9000 certification is needing payment not only to companies needing it as part of their in competition military store but in addition, simply to keep from being left out of their own markets. On the other hand, in a more or less parallel development, in have bitter feeling about years; the companies have also seen the better chances of working collaboratively with their suppliers and persons getting goods from store. This working together has led to the making 
(money) by stamping metal of the noted idea of supply chain business managers (SCM).

\section{OBJECTIVE}

This study lies right at the combination of these two highly topical ideas, quality management and CM. Primarily, It has been asked whether accompany indulged in quality management improves its SCM. Based on facts and other evidence, the answer has to be yes; otherwise, this would not be understanding/explaining quality management in its widest and most correct sense. However, in the present business climate, in which most companies has begin the quality management in supply chain and starts with quality promise, which in practice means getting the ISO 9000 standard certificate, Does the same thing happen?

In other word, when a company gets the ISO 9000 certificate, does its SCM improve? In this case, the question is no longer answer till this certification is not taken at supplier and as well as dealer ends. For this reason, a data base study is carried out in this study and key factors and sub factors of quality management is analysed. And effects of quality management on the supply chain are also discussed and analysed in this study with the help of AHP. This study begins with a brief description of the main objective followed by a review of the supply chain and quality management in a world leading automotive industry. Finally, the paper concludes with a discussion of results.

\section{EVALUATION FRAMEWORK}

In the relation of international logistics, benchmarking structure such as Quality Assurance Accreditation (QAA), Total Quality Management (TQM) and internal Composite Strategy Modelling tools can be blend to maximize logistics performance. This project assesses the contribution of QM systems to performance enhancement in supply chain. We have used both internal and external quality management systems in order to provide optimal solutions for the success supply chain.

We have used both internal and external quality management systems in order to provide optimal solutions for the success supply chain.

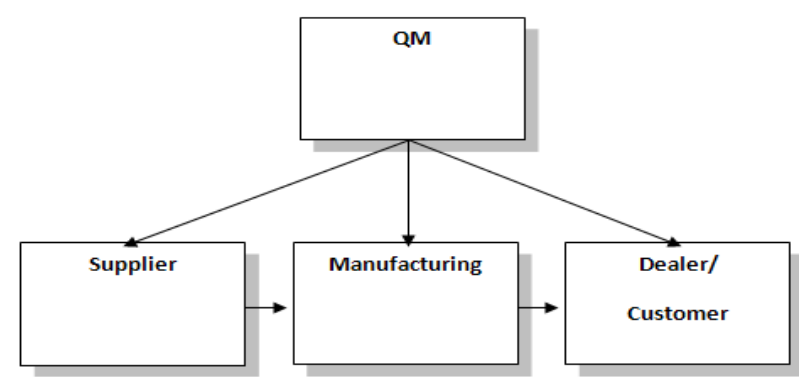

According to this framework, Quality management in supply chain of an organization will depend on its successful implementation of quality management system. We will analyse and prioritize that which quality system is best in supply chain. In below Fig all the critical factors are given

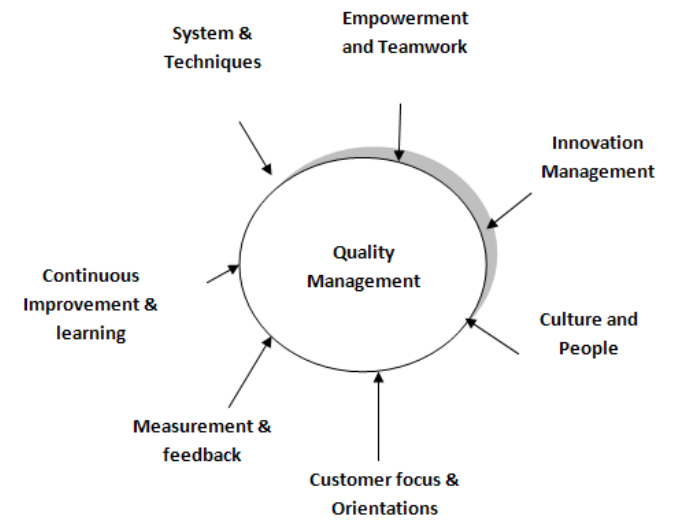

Application of AHP to Prioritize the Key Factors in Supply Chain

Quality management (QM) generally views as a philosophy that aim is to achieve customer happiness through prolongs improvement and troupe task. The transformation towards QM is paired with its diffusion, from the manufacturing to the service sector and onto public services (Dale, 1999). In many organizations Implementation of QM has become a top management mission to achieve business benefits, better product quality, higher customer happiness, less quality cost and improved supply chain. Some recent studies advocated that many organizations launched QM programs have gained any positive results. There have been several approaches and model suggested for the QM introduction and implementation. This paper presents main finding of a recent study that investigated the critical factors of quality management affecting the implementation of QM in supply chain. A general hierarchy model was elaborated to help prioritization these factors and formulate strategy for quality management implementation in supply chain.

\section{Critical Factors and Sub Factors of Quality Management}

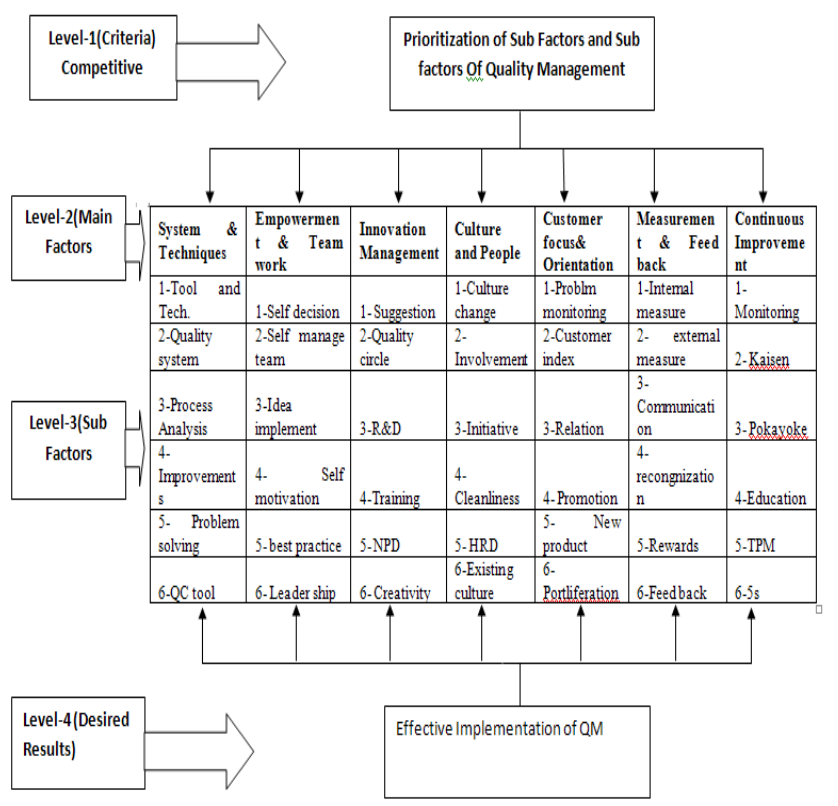




\section{Analytic Hierarchy Process}

AHP is a mathematical technique used for multi-criteria decision-making. In a way it is better than other multi-judging requirements ways of doing things, as it is designed to incorporate able to be touched/real as well as non-able to be touched/real factors especially where the (open to opinion and judging; not black-and-white) judgments of different people make up/be equal to an important part of decision making (Saaty, 1980). Apart from other facts, this comes from the special structure of the AHP, which follows the (intelligent/obvious) way in which managers solve problems, and in its easy handling compared with other multi judging requirements decision-making procedures. That's the reason for the (in an obvious, gut-feeling way) solved decision problems can now be solved as procedure-orientated using AHP. The use of AHP leads to both, more clearness/open honesty of the quality of management decisions and an increase in the importance of AHP (Ossadnik W\& Lange O, 1999). The stages of AHP are described below:

Firstly, the decision points are figured out. Then, the factors influencing a decision are described. The number of decision points is shown with " $m$ " and the factors affecting the decision points are presented with " $n$ ".

\section{Establishing a Comparison Matrix of the Factors}

The comparison matrix is a square matrix with $n \times m$ dimensions. The evaluation factors make up the rows and columns of the matrix. Using the relative importance scale, as shown in Table 1, makes the comparisons. Since the values on the diagonal represent the same factor, they become 1 . If the preference is used in favor of the factor in the row when the factor in any row is compared with the factor in the column, fraction (1/importance value) is preferred.

\begin{tabular}{|c|c|c|}
\hline \multicolumn{3}{|c|}{ Table l: Scale of relative importance } \\
\hline $\begin{array}{l}\text { Intensity of } \\
\text { relative }\end{array}$ & Importance & Definition explanation \\
\hline 1 & Equal Importance Laval & Two elements have equal importanceregarding the element in higher leval \\
\hline 3 & Week Dominance & Experience or judgement slightly favors one element \\
\hline 5 & Strong Dominance & Experiences or judeement strongly favors one element \\
\hline 7 & DemonstratedDominance & Dominance of one element proved in practice \\
\hline 9 & Absolute Dominance & The highest order dominance of one element over another \\
\hline $2,4,6,8$ & Intermediate Values & Compromise is needed \\
\hline
\end{tabular}

Determining Percentages for the Importance Distribution of the Factors

The B row vector with $n \times 1$ dimensions is established by using row vectors building the comparison matrix for importance distribution.

$$
B i=. b i j . n \times 1 \ldots, i=1,2, \ldots, n \ldots,(1)
$$

The components of this vector are calculated by using Formula 2, with the utilization of the elements of the comparison matrix (aij). In other words, the elements of the B row vector are calculated by dividing the elements in the lines of the comparison matrix with the row sums $[7,8]$.
Then, they got $\mathrm{n}$ times $\mathrm{B}$ row vector is structured in a matrix format and the middle values of the elements in every row are calculated. The $\mathrm{n}$ value got in this way gives the percentage distribution of value factors, that is, importance values (W priority vector with $\mathrm{n} \times 1$ dimensions).

$$
B i j=
$$

\section{Finding the Percentage Importance Distribution in $m$ Decision Points for Every Factor}

In this stage, the percentage of importance distribution related to every factor is allocated as explained in b and c. In other words, pair-wise comparisons and matrix operations as explained in c are repeated as many times as the number of factors.

However, in this time the dimensions of comparison matrices to be used in decision points for every factor will become $\mathrm{m} \times \mathrm{m}$. After every comparison operation, $\mathrm{S}$ column vectors with $m \times 1$ dimensions and showing percentage distribution of every evaluated factor to the decision points are obtained [9].

\section{Reaching the Result Distribution in the Decision Points}

In this stage, $n$ times $\mathrm{S}$ column vectors are all brought together. So, a matrix with $m \times n$ dimensions is obtained. When this matrix is multiplied with the $W$ priority vector the percentage distribution of decision points (alternatives) is got.

\section{Result AND DisCUSSION}

\begin{tabular}{|c|c|c|c|c|c|c|c|}
\hline criteria preferences & $\begin{array}{l}\text { System \& } \\
\text { Techrniques }\end{array}$ & \begin{tabular}{|c|} 
Emporrer \& \\
Team \\
\end{tabular} & $\begin{array}{l}\text { Innovation } \\
\text { mangegment }\end{array}$ & \begin{tabular}{|c|} 
Culture \& \\
People \\
\end{tabular} & \begin{tabular}{|c|} 
Customer \\
Poous \\
\end{tabular} & $\begin{array}{l}\text { Measure and } \\
\text { Pead back }\end{array}$ & $\begin{array}{l}\text { Continuous } \\
\text { Improvement }\end{array}$ \\
\hline System \& Techniquat: & 1 & 12 & 1 & 12 & & 12 & 12 \\
\hline Empower \& Team & 2 & ! & $T$ & $1 / 4$ & $1 / 2$ & ! & $\overline{12}$ \\
\hline $\begin{array}{l}\text { Innovation } \\
\text { mangegment }\end{array}$ & 12 & 1 & 1 & $1 / 4$ & ? & 1 & 1 \\
\hline Culture \& Peopla & 4 & 4 & 4 & 1 & 3 & 7 & 1 \\
\hline Customer Focus & $\overline{12}$ & 2 & $\overline{112}$ & $1 / 3$ & $T$ & $T$ & 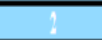 \\
\hline Measure and Paed base & 2 & T & 1 & 112 & 1 & 1 & 2 \\
\hline \begin{tabular}{c|} 
Continuous \\
Improvement
\end{tabular} & 1 & ? & 1 & $1 / 2$ & $1 / 2$ & 12 & 1 \\
\hline
\end{tabular}

\section{Table?}

Cl:0,11966 CR:0,0886 $\quad \lambda: 7,7176$

Table 3

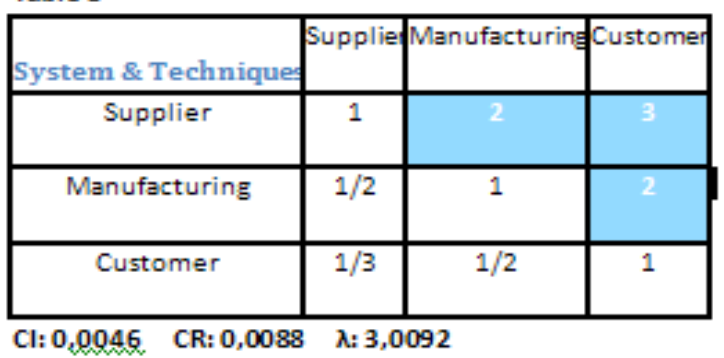


Table 4

\begin{tabular}{|l|c|c|c|}
\hline Empower \& Team & Supplier & Manufacturing & Customer \\
\hline Supplier & 1 & 2 & 1 \\
\hline Manufacturing & $1 / 2$ & 1 & 2 \\
\hline Customer & 1 & $1 / 2$ & 1 \\
\hline Cl: $0,1087 \quad$ CR: 0,2090 & $\lambda: 3,2174$
\end{tabular}

Table 5
\begin{tabular}{|c|c|c|c|}
\hline Innovation managemen & Supplier & Manufacturing & Customer \\
\hline Supplier & 1 & 1 & 2 \\
\hline Manufacturing & 1 & 1 & 1 \\
\hline Customer & $1 / 2$ & 1 & 1 \\
\hline
\end{tabular}

Cl: 0.0268 CR: $0,0515 \quad \lambda: 3,0536$

Table 6
\begin{tabular}{|l|c|c|c|}
\hline Culture \& People & Supplier & Manufacturing & Customer \\
\hline Supplier & 1 & 3 & 2 \\
\hline Manufacturing & $1 / 3$ & 1 & 2 \\
\hline Customer & $1 / 2$ & $1 / 2$ & 1 \\
\hline
\end{tabular}

Cl: $0,0678 \quad$ CR: $0,1304 \quad \lambda: 3,1357$

Table 7

\begin{tabular}{|c|c|c|c|}
\hline Customer Focus & Supplier & Manufacturing & Customer \\
\hline Supplier & 1 & 3 & \\
\hline Manufacturing & $1 / 3$ & 1 & 2 \\
\hline Customer & $1 / 2$ & $1 / 2$ & 1 \\
\hline
\end{tabular}

CI: 0,0678 CR: 0,1304 रे: $\mathbf{3 , 1 3 5 7}$

Table 8

\begin{tabular}{|c|c|c|c|}
\hline Measure and Feed bacl & Supplier & Manufacturing & $\begin{array}{c}\text { Customa } \\
\mathrm{r}\end{array}$ \\
\hline Supplier & 1 & 1 & 2 \\
\hline Manufacturing & 1 & 1 & \\
\hline Customer & $1 / 2$ & $1 / 2$ & 1 \\
\hline
\end{tabular}

CI: 0,0000 CR: $0,0000 \quad \lambda: 3,0000$
Table 9

\begin{tabular}{|c|c|c|c|}
\hline Continuous Improvemen & Supplie & Manufacturing Custome \\
\hline Supplier & 1 & & \\
\hline Manufacturing & $1 / 4$ & 1 & 3 \\
\hline Customer & $1 / 5$ & $1 / 3$ & 1 \\
\hline
\end{tabular}

CI: $0,0430 \quad$ CR: 0,0827 i: 3,0860

Table 10

\begin{tabular}{|c|c|c|c|c|c|c|c|}
\hline $\begin{array}{l}\text { Criteria } \\
\text { preferences }\end{array}$ & $\begin{array}{l}\text { System \& } \\
\text { Technique }\end{array}$ & $\begin{array}{l}\text { Emporier } \\
\text { \& Team }\end{array}$ & $\begin{array}{l}\text { Innoration } \\
\text { management }\end{array}$ & $\begin{array}{l}\text { Culture } \\
\text { \& People }\end{array}$ & Customer Focus & $\begin{array}{l}\text { Measure an } \\
\text { Feed back }\end{array}$ & $\begin{array}{l}\text { CContinuous } \\
\text { Improvemen }\end{array}$ \\
\hline Supplier & 0,5396 & 0,4126 & 0,4126 & 0,5472 & 0,5472 & 0,4000 & 0,6738 \\
\hline Manufacturing & 0,2970 & 0,3275 & 0,3275 & 0,2631 & 0,2631 & 0,4000 & 0,2255 \\
\hline Customer & 0,1634 & 0,2599 & 0,2599 & 0,1897 & 0,1897 & 0,2000 & 0,1007 \\
\hline
\end{tabular}

VI. CONCLUSION

Table 11

\begin{tabular}{|c|c|}
\hline & Result \\
\hline System \& Techniques & 0,1166 \\
\hline Empower \& Team & 0,1008 \\
\hline Innovation management & 0,1091 \\
\hline Culture \& People & 0,2912 \\
\hline Customer Focus & 0,1187 \\
\hline Measure and Feed back & 0,1416 \\
\hline Continuous Improvement & 0,122 \\
\hline
\end{tabular}

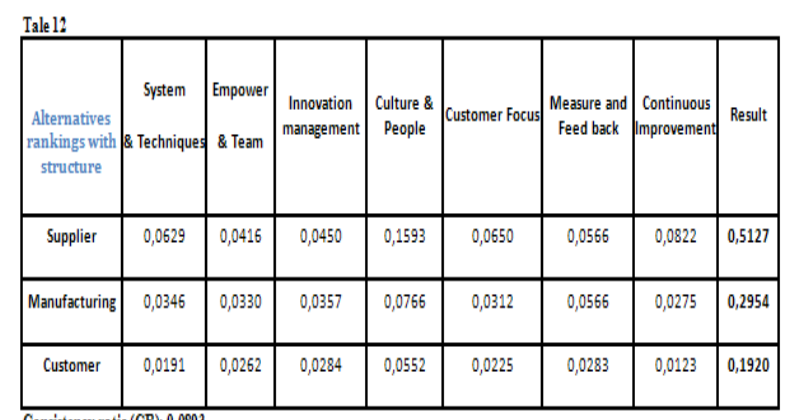

Consistency ratio(CR): 0,0993

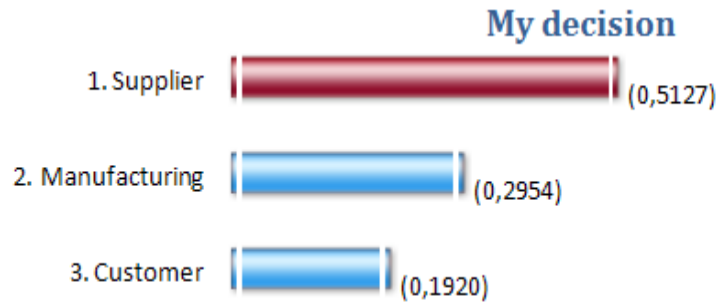

The Overall rating of all three areas are calculated and shown in above Table. The supplier has the maximum rating i.e. 0.5. The supplier has the best quality management at supplier end. 
To be remained most competitive the Organization is giving priorities in cultural and people development and measurement and feed back to reduce product cost and enhance quality. For not going in competition market an organization must have unbroken stretch getting better throughout the organization with tending to new map to get better its supply chain. The organizations should not Target only end results but should undergo growth its quality system in all area of supply chain. The cultural \& people and measurement \&feed back are the two factors prioritized i.e. 0.291 and 0.14 respectively in AHP calculation which makes a supply chain and quality management best integration. Any Organization can have best quality management in supply chain by enhancing the people culture and measurement \& feedback system. A crucial element in the formulation of any business strategy to build people culture is having the right information about the industry and the environment, at the right time. In an competition industry, this gives sense of words into having way in to safe, good and giving legal cause information about competitors, as well as the in competition general condition in the industry, including information about competitors. However, quality business managers are a journey and unbroken stretch getting better and not a place where one is going. The final dimension should be discussed is innovation. Innovation is critical to sustaining a competitive edge. In the past fifty or so years, most innovation has come from the United States, Europe, or Japan. This almost seems inevitable given the comparative advantage these countries have enjoyed in terms of supplier development, manufacturing and consumer relation. Everyone of the company needs to clarify their roles and responsibilities.

Even the company has made a very good system of balanced scorecard to measure the performance. The man benefit of the development of the performance system is to provide a structure for measuring the performance in manufacturing and reduce dependence on human expertise and judgments.

\section{REFERENCES}

[1] Aitken, J., et al., (2002) "Understanding, implementing and exploiting agility and leanness", International Journal of Logistics: Research and Applications, Vol. 5, No. 1, pp.59-74.

[2] Anderson JC, et al.(1995), "analytic model of a theory of quality management underlying the Deming management method", preliminary empirical findings. Decision Sciences, Vol. 26, No.4, pp. 637-658.

[3] Beresford, et al, (1996) "ISO 9000 and the British transport industry", ISO 9000 News, Vol. 5, No. 4, pp.21-24.

[4] Black SA and Porter LJ.(1996) "Identification of the critical factors of TQM, Decision Sciences", Vol.27, No. 1, pp. 1-22.

[5] Campbell, J. and Sankaran, J. (2005), "An inductive framework for enhancing supply chain integration", International Journal of Production Research, pp. 3321-3351

[6] Copacino WC.(1996) "Seven supply-chain principles", Traffic Management Vol. 35, No. 1, pp. 60.

[7] Coyle JJ, et al, (1996). "The management of business logistics", 6th ed. Mason, Ohio: West Publishing Company;

[8] Cronin, J.J. and Taylor, S.A. (1992) "Measuring service quality: a reexamination and extension", Journal of Marketing, Vol. 56, No. 3, pp.55-68.

[9] Cronin, J.J. and Taylor, S.A. (1992) "Measuring service quality: a reexamination and extension", Journal of Marketing, Vol. 56, No. 3, pp.55-68.
[10] Croom, S.R., et al, (2000) "Supply chain management: An analytical framework for critical literature review". European Journal of Purchasing and Supply, pp. 67-83.

[11] Crosby, P.B. (1979), "Quality Is Free, McGraw-Hill”, New York, NY.

[12] Crosby, P.B. (1996), "Quality Is Still Free: Making Quality Certain in Uncertain Times", McGraw-Hill, New York, NY.

[13] Dale, B.G. (1999), "Managing Quality", Blackwell Publishers, Oxford, Vol. 3, Pp. 23 25

[14] Davis T.(1993)," Effective supply chain management", Sloan Management Review Vol..12, pp.35-46.

[15] Deming, W.E. (1986) "Out of the Crisis: Quality, Productivity and Competitive Position", Massachusetts Institute of Technology, Centre of Advanced Engineering Study, CambridgeUniversity Press, Cambridge.,pp 125-123

[16] Dow D, et al, (1999),"Exploding the myth: do all quality management practices contribute to superior quality performance" Production and Operations Management Vol.8, No.1, pp. 1-27.

[17] Fawcett, S.E. and Magnan, G.M. (2002) "The rhetoric and reality of supply chain integration", International Journal of Physical Distribution and Logistics Management, Vol. 32, No. 5, pp.339-361.

[18] Feigenbaum, A.V. (1991) "Total Quality Control, McGraw-Hill", London.Vol. 3, pp. 230-231.

[19] Flynn BB, et al, (1995)," The impact of quality management practices on performance and competitive advantage". Decision Sciences, Vol.26, No.5, pp. 659-692.

[20] Flynn, B.B, et al, (1994), "A framework for quality management research and an associated measurement instrument". Journal of Operations Management, Vol.2 pp.339-366.

[21] Flynn, B.B., Saladin, B. (2001). "Further evidence on the validity of the theoretical models underlying the Baldrige criteria". Journal of Operations Management, Vol. 19, pp.617-652.

[22] Forza, C. (2002), "Surveys: survey research in operations management: a process-based perspective", International Journal of Operations and Production Management, Vol. 22, No. 2, pp.152-194.

[23] Fynes, B., Voss, C., (2002). "The moderating effect of buyer--supplier relationships on quality practices and performance. International Journal of Operations \& Production Management", Vol. 22, pp. 589-613.

[24] Groves G and Valsamakis V.(1998), "Supplier-customer relationships and company performance". International Journal of Logistics Management Vol.9, No.2, pp. 51-64.

[25] Ho, S.K. (1997) "Are ISO 9000 and TQM routes to logistics excellence", Logistics Information Management, Vol. 10, No. 6, pp.275-283.

[26] Juranet al. (1999) "Juran's Quality Handbook", 5th ed., McGraw-Hill, London., pp 95-99

[27] Juran, J.M. (1986) "Quality Control Handbook, McGraw-Hill", London.,pp 205-206

[28] Juran, J.M. and Gryna, F.M. (1993), "Quality Planning and Analysis", 3rd ed., McGraw-Hill, New York, NY.

[29] Kanji, G. and Asher, M. (1996) "100 Methods for Total Quality Management", Sage Publications, London.

[30] Kearney, A.T. (1992) "Achieving Customer Satisfaction Leadership in Europe", Report Vol. 33, No. 8, pp.701-719.

[31] Kearney, A.T. (1992) "Achieving Customer Satisfaction Leadership in Europe", Report No. 37.

[32] Kemppainen, K. and Vepsalainen, A.P.J. (2003) "Trends in industrial supply chains and networks", International Journal of Physical Distribution and Logistics Management, Vol. 33, No. 8, pp.701-719.

[33] Krause, DR.(1997) "Supplier development: current practices and outcomes. International Journal of Purchasing and Materials Management", Vol. 33, No.2 pp. 12-19.

[34] Kuei, C,et al (2001). "The relationship between supply chain quality management practices and organizational performance". The International Journal of Quality\& Reliability Management, Vol.18, No.8, 864-872.

[35] Larson PD andRogers DS.(1998), "Supply chain management: definition, Growth and approaches". Journal of Marketing, Vol. 6, No 4, pp. 1-5. 